\section{But today, there is naming of parts}

\author{
J. S. Jones
}

Keywords in Evolutionary Biology. Edited by Evelyn Fox Keller and Elizabeth A. Lloyd. Harvard University Press: 1992. Pp. 414. \$45, £39.95.

THE Maoris, it is said, have 35 different words for dung. To Maori philologists, if such exist, each term has - no doubt an exquisitely distinct meaning. To the rest of us, dung is, well, dung. We may occasionally use different words to describe it, but it's all the same stuff really.

If you thought that the same was true for familiar biological stuff such as EXTINCTIONS, GENES or INDIVIDUALS, this book shows how wrong you were. Each - as do most of the 40 keywords discussed here - turns out to have hidden assumptions and ambiguities; so much so that some may be best abandoned.

Any science, such as evolution, that is still trying to define its terms more than a century after it began has real problems. Part of the semantic quandary arises from evolutionists' habit of picking up words that have already been used by someone else. COMPETITION, ADAPTATION, STRUGGLE and ALTRUISM: we all know what they signify in daily life, and easily slip into thinking that they must mean the same in science. The vaguer the concept, the easier it is to use. Muddled thinking has a distinguished pedigree. After all, Darwin himself admitted to using "the struggle for life" in a "large and metaphorical sense".

In evolution, there has always been a tendency for words to take precedence over thought. Take Herbert Spencer. In his obituary, the London Times, with the shoddy judgement which has characterized that newspaper ever since, wrote that "England has lost the most widely celebrated and influential of her sons

breathing life into the dead bones of science". Spencer was, without doubt, the most famous Darwinist of his day (although, according to P. Bowler's definition in Keywords, he was more a LAMARCKIAN, as he believed that the struggle for existence caused individuals to improve themselves and that this improvement was passed to generations yet unborn).

Spencer's definition of EVOLUTION was "an integration of matter and a concomitant dissipation of motion; during which the matter passes from an indefinite, incoherent homogeneity, to a definite, coherent heterogeneity, through continuous differentiations and integrations". The Victorian mathematician Kirkman parodied this (and it deserves parody) as "a change from a nohowish untalkaboutable all-alikeness to a somehowish and in general talkaboutable notall-alikeness by continuous somethingelseifications and sticktogetherations".

But what is evolution? In Keywords, R. Richards points out that its meaning has gone full circle since it began. In its Latin root it referred (as readers of Nature will of course know) to the unfolding of a scroll. As Cicero so memorably put it: "Quid poetarum evolutio voluptatis affert" - What pleasure does the reading of the poets provide! Swammerdam used the word first in biology to refer to the unfolding shape of an insect during its metamorphosis, in his view the expression of a fixed adult form which was preformed in the egg. In the eighteenth century, as the idea of preformation declined, it shifted to mean the expression in a developing embryo of the structures of more primitive species what is now referred to as recapitulation. Then it changed again to mean something close to the way in which it is now used, the gradual transformation of one species into another.

SPECIES, it turns out, is so hard to define that it needs three separate and conflicting interpretations. P. F. Stevens makes a historical survey, concentrating on the taxonomists' view of a species as just a rank in the great chain of being. J. Dupré asks whether members of a species belong to a natural set - or are they a kind of individual? He does not come up with an answer (although he manages to take a swipe at the biological species concept on the way). M. B. Williams takes a more relaxed view of how the word is used today, but also fails to find the key. Some modern definitions have an oddly Spencerian ring - one, from 1989 , has it that a species is "the most inclusive population of individuals having the potential for phenotypic cohesion through intrinsic cohesion mechanisms", and there is, with Spencer, the same sense of trying to define the undefinable (which would mean, in any other science, the unusable). All this lexical confusion makes it easy to forgive Darwin for having a written a book about almost everything except the origin of species.

Well, what about EXTINCTION? Simple enough, surely - deceased, no more, an ex-species. But no; as J. Damuth points out, there are subtleties even in being dead. The mere fact of extinction was once hard for creationists to bear, and President Thomas Jefferson enjoined the explorers Lewis and Clark to keep a keen look-out for the mammoths that must be roaming the United States somewhere. In spite of the 4,000-yearold stragglers reported a few weeks ago in Nature, the mammoths do seem to have departed. Nevertheless, even for a living species, extinction is the norm, as most of its members are defunct. In addition, the whole idea of evolution assumes that even when a species has disappeared for ever, some of its descendants are flourishing. Such species are, apparently - and rather like Monty Python's parrot - only PSEUDOEXTINCT.

When we get to GENE it is beginning to be time to give up hope. P. Kitcher's definition is that a gene is anything a competent biologist chooses to call one. At least this definition is simple unlike MONOPHYLY: "T is monophyletic, if and only if there exists a species $\mathrm{s}$, a member of $\mathrm{T}$; and for any other species $d$, if $d$ is a member of $T$, then $s$ is an ancestor of $d$ ".

A lot of this might seem like nitpicking, but most of it is essential. It is difficult to argue about speciation or group selection without everyone being sure that they are talking about the same thing. Keywords makes it clear that for much of the time they are not. Much of the problem arises from the fact that many terms - ADAPTATION, COMPETITION and NICHE, for example - include both process and pattern: that which exists, together with how it was attained. Sometimes what seems a trivial point of definition alters the entire argument. A failure to understand the precise meaning of HERITABILITY led to the whole wearisome controversy about nature and nurture in controlling human intelligence.

At an American sociologists' congress a few years ago, 'love' (not mentioned here) was defined as "the cognitive affective state characterized by intrusive and obsessive fantasising concerning reciprocity of amorant feelings by the object of amorance". It's better than saying that it is like a violin, but it's not much help to those faced with the problem. The same might be said of this book - it helped me to understand why I feel so confused about evolution, but did not come up with what the right answers might be.

J. S. Jones is in the Department of Genetics and Biometry, University College London, London NW1 2HE, UK.

New Journals issue
This year, Nature's annual new journals
review supplement will appear in the issue o
7 October. Publishers and learned societies
are invited to submit journals for review.
Journals that first appeared during or after
June 1991 and issued at least four separate
numbers by the end of April 1993 will be
considered. Frequency of publication must
be at least three times a year. For further
information please see the 22 April issue of
Nature, or telephone Peter Tallack on
071-836-6633 (011-44-71-836-6633
from the United States), extension 2414 .

